\title{
INFANCIA Y TÉCNICAS DE REPRODUCCIÓN ASISTIDA.
}

UNA APROXIMACIÓN BIOÉTICA

\author{
Renzo Paccini Vega \\ Facultad de Teología Pontificia y Civil de Lima \\ paccini.r@gmail.com
}

Resumen: Las discusiones sobre la licitud ética de las Técnicas de Reproducción Asistida (TERA) suelen enfatizar los intereses de los adultos, muchas veces teñidos de sentimientos de compasión. El presente trabajo pretende dar una nueva luz al debate presentando un análisis bioético de las TeRA, principalmente de la Fertilización in vitro con transferencia de embriones, desde los intereses de los niños generados por ellas. Primero se describen aspectos técnicos y científicos, que revelan a las TERA como procedimientos no terapéuticos de muy baja eficacia y con efectos futuros aún desconocidos, lo que las califica de «experimentales». Luego, asumiendo a la persona humana como la medida fundamental de la valoración ética, se resaltan los valores del niño inevitablemente vulnerados en el procedimiento, como son su vida física y dignidad humanas, así como su salud, su filiación e identidad y su libertad. Se concluye que las TERA son actos intrínsecamente malos.

* Renzo Paccini Vega se graduó de médico general en la Universidad Peruana Cayetano Heredia. En el 2000 obtuvo la maestría en Bioética en el Ateneo Regina Apostolorum (Roma), y el doctorado en la Universidad Católica del Sagrado Corazón (Roma) en el 2004. Actualmente, es profesor de Bioética en la Facultad de Teología Pontificia y Civil de Lima. 
Palabras clave: técnicas de reproducción asistida, fertilización in vitro, bioética, embrión, niño, persona.

INFANCY AND REPRODUCTION ASSISTED TECHNICS.

\section{A BIOETHICS APPROXIMATION}

Aвstract: The arguments for the ethical admission of Assisted Reproductive Technologies (ART) usually emphasize the interests of adults and are many times full of feelings of compassion. The present work intends to set up a debate with a new light by presenting an ART bioethical analysis, especially on that of vitro fertilization by transfer of embryos, and looking at it from the perspective of the interests of children generated by it. First, technical and scientific aspects are described. These reveal ART as consisting of nontherapeutic procedures with very poor efficacy and with yet unknown future effects, which in turn classify them as «experimental». Afterwards, assuming that the human person is the fundamental reference of ethical value, the values of the child, who is inevitably vulnerable in this procedure, are highlighted, such as his human physical life and dignity, his health, filiation and identity and freedom. It is concluded that ART methods imply intrinsically evil acts.

KeYwords: assisted reproductive technologies, in vitro fertilization, bioethics, embryo, child, person. 


\section{INTRODUCCIÓN}

O e puede decir que es algo novedoso abordar la realidad de las Técnicas de Reproducción Asistida (Tera) desde la perspectiva del niño, "poniéndonos en sus zapatos». Lo común es hacerlo desde la perspectiva de los llamados "padres» o «los que desean ser padres», o — de modo más general - «los que quieren tener un hijo»; que, en suma, son los adultos. Es decir, usualmente el abordaje de las TERA en las discusiones éticas y legales es desde la perspectiva de los adultos y sus intereses de adultos; no desde la perspectiva de los niños. Además, desde la perspectiva del adulto, un elemento que va por delante en las discusiones médicas, sociales, éticas y legales suele ser el sentimiento de compasión, que cierra - $\mathrm{O}$ al menos distorsiona fuertemente- la posibilidad de reflexionar de manera objetiva, descalificando en los hechos a quien se insinúa con una apreciación diferente acerca de las TERA, porque ¿quién estaría en contra de aliviar el sufrimiento de una pareja de esposos que luego de uno o más años de matrimonio, ve que todo en sus vidas se derrumba porque no llega el ansiado hijo?, ¿quién osaría oponerse a aliviar el sufrimiento de esta pareja?, ¿quién se atrevería a cerrarles el acceso a las TERA? De esa manera la compasión, como sentimiento, puede obnubilar nuestra razón y hacernos perder de vista la verdad de los hechos.

Creo que el ejercicio de mirar las Tera desde la perspectiva del niño permitirá distinguir elementos objetivos a tener en cuenta al momento de tomar decisiones éticamente correctas. Asimismo, se podrán asumir las consecuentes medidas legales a favor de todos y cada uno de los integrantes de la familia humana, especialmente los más débiles de nuestra sociedad.

Hoy se atribuye a las Tera el 1\% de los nacimientos en EEUU, mientras que en algunos países europeos el cálculo llega hasta el 2 ó 3\% de los nacidos vivos (cf. Centers for Disease Control and Prevention 
2007; Andersen 2005). Sin embargo, existe mucha confusión respecto a si es éticamente correcto o no recurrir a las TERA — y específicamente la Fertilización in vitro con transferencia de embriones, FIV- para tener un hijo. Y existe más desconocimiento todavía de lo que en dichas técnicas ocurre realmente, sobre todo, de las implicancias para los niños. Por ello, voy a articular mi exposición en dos pasos: en el primero serán expuestos los datos biomédicos; y en el segundo, se desarrollará una reflexión ética que permita entrever los valores en juego y dar una apreciación de licitud o ilicitud ética de las TERA; para llegar finalmente a las conclusiones.

\section{LOS DATOS BIOMÉDICOS}

\subsection{Aspectos téCNICOS geNERALES}

Según la definición aceptada, por TERA se comprende «todos los tratamientos o procedimientos que incluyen manipulación in vitro de ovocitos o esperma humanos, o embriones, con el propósito de establecer un embarazo; incluye - aunque no solo- la fertilización in vitro con transferencia de embriones, la transferencia intra-tubaria de gametos, de cigoto, de embrión, la criopreservación y la donación de gametos y embriones y la maternidad sustituta o subrogada; y no incluyen la inseminación asistida o artificial» (Zegers-Hochschild ET AL 2009: 2685). Nos referiremos aquí a las TERA en conjunto, acentuando más en la Fiv, de la que todo el resto de ellas deriva.

Las TERA no constituyen propiamente un tratamiento médico contra la infertilidad; de hecho, no la curan. No son un procedimiento terapéutico; son más bien un procedimiento alternativo con el que se trata de lograr un embarazo que llegue a término, es decir, que finalice con el nacimiento de, al menos, un bebé. El registro estadístico y la evaluación de 
las Tera desde el punto de vista propiamente técnico es difícil, porque no existe uniformidad de protocolos ni de criterios entre los diferentes Centros que las realizan, ni todos ellos registran sus actividades regularmente, ni con los mismos parámetros. A continuación señalaremos los siguientes aspectos en torno a los procedimientos de la FIV

a) El procedimiento estándar de la FIV hoy es ampliamente conocido. Participan un gineco-obstetra y un biólogo, que son el equipo básico para poder realizar el procedimiento, al que suele sumarse una obstetriz como auxiliar. De manera resumida, la secuencia de pasos es la siguiente:

- Se extraen y tratan los gametos masculinos y femeninos; estos últimos se obtienen sometiendo previamente a la mujer a una hiperestimulación hormonal, que comentaremos más adelante.

- Luego de preparar los gametos, se procede a la fertilización in vitro y al cultivo durante 3 a 5 días de los embriones obtenidos. Aquí se debe hacer notar algo importante: la fertilización que ocurre en el laboratorio es lo que usualmente ocurre en el tracto genital femenino - normalmente en las trompascuando la concepción del ser humano es natural. Esta fusión de gametos llamada concepción, fecundación, o fertilización, es el «tiempo cero» de la existencia de cada ser humano, el instante en el que inicia «su» vida (cf. Moore 1998; O’Rahilly 2001). La fusión — unión de las membranas celulares — de estas dos células altamente especializadas, como son los gametos, genera una nueva unidad biológica individual viva, 
perteneciente a la especia humana, que comanda su desarrollo (cf. Serra 2003; Sgreccia 2008) de forma continua — sin interrupciones ni eventos saltatorios-, coordinada - no de manera aleatoria o al azar- y gradual — con una lógica en la construcción de estructuras biológicas, de menos complejas a más complejas-. Estamos pues, ante un ser humano como nosotros en el primer momento de su existencia, cuya cuerpo lo constituye una sola célula. La biología nos enseña que esta primera morfología unicelular de todo ser humano dura menos de 24 horas, y que sorprendentemente en el momento en que se divide para existir como un organismo vivo compuesto de dos células, el eje de su cuerpo queda ya constituido, lo que ha llevado a la ciencia a afirmar que hay cosas de nuestro destino que quedan fijadas en el «día uno» de nuestra existencia (cf. Pearson 2002).

- Se continúa en el procedimiento con la transferencia de embriones, habitualmente a la cavidad uterina. ${ }^{1}$ En este tercer paso, se realiza in vitro una selección previa de los

1 En la Fiv — aunque se sigue verificando que la concepción, es decir, la fusión de los gametos marcan el inicio de la existencia de un nuevo ser humano- ocurre una doble dicotomía en relación al proceso natural de la concepción: a) el inicio de la maternidad ya no coincide con el inicio del embarazo: en la Fiv la mujer ya es madre de los embriones obtenidos in vitro sin tenerlos ella en su cuerpo, por lo tanto, sin estar embarazada; y b) el inicio de la vida del hijo ya no coincide con el inicio del embarazo en la madre: el embarazo se inicia en la mujer recién 3 a 5 días después de la generación de los hijos en el laboratorio, cuando estos —en estadío embrionario- le son transferidos y prosiguen su desarrollo, si logran implantarse en el endometrio uterino. Esto dio pie a que a inicio de los años setenta se decida, de manera arbitraria, que todo embarazo se inicia con la implantación del embrión, extendiendo a los embarazos naturales lo que solo se verifica en la Fiv. Siguen esa postura la Organización Mundial de la Salud y todos los organismos interesados en promover el aborto y la experimentación con embriones humanos. 
embriones a transferir al cuerpo de la madre; esto no suele ser mencionado explícitamente como un paso de la técnica. Dicha selección embrionaria consiste en descartar los embriones que son considerados, por sus características morfológicas o cromosómicas o genética como «inaptos»o «menos aptos» para lograr implantarse y proseguir su desarrollo en el seno materno. Es una primera criba en el proceso, que elimina embriones humanos mediante una acción directa a manos del operador de la técnica. Prácticamente nunca se transfiere un solo embrión, lo usual es transferir tres.

- Una vez logrado el embarazo — si es que más de uno de los embriones transferidos logran implantarse en el endometrio uterino para proseguir con su desarrollo dentro de la matriz de la mujer madre- se procede a la reducción del embarazo multifetal o reducción embrionaria. Ello consiste en eliminar, mediante la inyección de una solución salina con potasio, uno o más de los sacos gestacionales donde están contenidos los embriones, según diferentes criterios de selección. La finalidad de esta medida es aumentar la posibilidad de que al menos uno de los hermanos que se están gestando en el seno materno complete su desarrollo y pueda nacer, o disminuir los riesgos para la salud de la mujer madre portadora del embarazo múltiple, o simplemente terminar con un embarazo múltiple no deseado por quienes solicitaron la TERA con el deseo de tener solo «un hijo». Esta es la segunda instancia en el proceso en la que el operador de la técnica elimina embriones deliberadamente. 
- Finalmente, se procede al parto, por lo general mediante cesárea.

b) Vale la pena mencionar la variante técnica conocida como Icsi, siglas en inglés de la Inyección Intra Citoplasmática de Espermatozoide, empleada para el caso de esterilidad masculina, por ejemplo a causa de defectos de motilidad en los espermatozoides. Con esta variante no se espera — como en la FIV - que la fertilización ocurra espontáneamente in vitro, sino que literalmente se inyecta un espermatozoide en el citoplasma del ovocito. Se ha visto un marcado incremento del recurso a la ICSI a nivel mundial, sobre todo en América latina y Medio Oriente. ${ }^{2}$ Es difícil encontrar una explicación razonable para ello, porque no hay motivo para pensar que la infertilidad masculina se haya incrementado y tampoco se ha demostrado que la ICSI mejore los resultados en los casos de infertilidad de origen no masculino. Es posible que se esté optando más prontamente por esta variante cuando falla la FIV convencional. El incremento en última instancia «inexplicable» de la ICSI ha de ser tenido en cuenta, dado que recientemente se ha reportado un riesgo significativamente mayor de defectos de nacimiento en los niños concebidos con el uso de ICSI en comparación con la FIV convencional (cf. Davies et al 2012).

c) Variables en juego para ampliar la oferta de las TERA. Es también conocido que el abanico de posibilidades ofrecido por las TERA se han multiplicado con el concurso de dos variables cuya implicancia ética es más compleja:

2 Desde el año 2000 al 2002, la técnica de ICSI se ha incrementado de 54\% a $61 \%$ en Norteamérica, de $46 \%$ a $54 \%$ en Europa; en América latina, ha alcanzado el $76 \%$ y en el Medio Oriente, más del 92\% (cf. Mouzon et al 2009). 


\section{INFANCIA Y TÉCNICAS DE REPRODUCCIÓN ASISTIDA}

- la «donación» de gametos: cuando se emplean en el procedimiento gametos de la pareja solicitante de la TERA, la fecundación se llama "homóloga"; pero si uno o ambos gametos provienen de «donantes» externos a la pareja, entonces la fecundación es llamada "heteróloga»;

- la maternidad subrogada: permite que la gestación se desarrolle, de manera sustituta, en el cuerpo de una mujer distinta de la que solicitó la TeRA y/o de la que aportó el óvulo.

Ambas variables cada una por sí sola o sumadas, al multiplicar la participación de personas en el proceso de lograr el hijo deseado, causan la disrupción de las relaciones parentales y filiales, más allá de la natural relación «un padre-una madre-hijo». Si bien donar los gametos o recurrir a la maternidad subrogada, en sentido estricto, podrían no ser incluidas en el procedimiento técnico de la reproducción, hoy por hoy el recurso a ambos se ha incrementado muchísimo $^{3}$ y la oferta del mercado para acceder a estas variantes — en particular la maternidad subrogada — se ha globalizado, dando lugar al fenómeno del "turismo reproductivo», cuyo ejemplo más saltante lo constituye actualmente la India, que atrae a parejas de Estados Unidos, Australia, Europa y otros continentes (Universidad de Stanford, 2009). De hecho, el recurso a estas dos variables ha abierto las puertas a formas parentales y de filiación trastocadas.

3 En Estados Unidos aproximadamente el 12\% de las TerA realizadas son con gameto de donante (cf. Centers for Disease Control and Prevention 2011). En cuanto a la maternidad subrogada, prácticamente no se cuenta con estadísticas. En Estados Unidos, informes del Centers for Disease Control and Prevention (CDC) y de la Society for Assisted Reproductive Technology (SARI) muestran que el número de niños nacidos de madres subrogadas se duplicaron del 2004 al 2008, de 738 a 1400 bebés (cf. Gugucheva 2010). 
d) Junto con la donación de gametos y la maternidad subrogada, la congelación de embriones constituye una variable más de las TERA. La congelación abre la posibilidad de que los embriones que se emplean en una TERA puedan ser no solamente los "frescos», es decir, los apenas obtenidos mediante la FIV, sino los «sobrantes» de un procedimiento anterior, y que se conservaron «congelados». Así, los embriones «congelados» pueden ser destinados para varios fines que mencionaremos a continuación:

- para un segundo intento, cuando el primero fracasa;

- para «intentar» un segundo hijo nacido, en el futuro, cuando en el primer intento se obtuvo finalmente un bebé nacido vivo;

- para donarlos a otra pareja que recurre a las TERA;

- para ser usados en investigaciones científicas, lo que al final significa su destrucción; o finalmente,

- $\quad$ para ser descartados, es decir, eliminados. ${ }^{4}$

\subsection{AlgunOS ASPECTOS TÉCNICOS ESPECÍfICOS}

Las Tera como procedimiento desarrollan determinados pasos, de los cuales es preciso comentar algunos aspectos técnicos y científicos. Esto debido a la importancia que tienen no solo para entender la valoración ética posterior, sino porque generan repercusiones para el niño. A continuación mencionaremos dichas consecuencias:

4 En los países donde las Tera son reguladas mediante ley, como es el caso del Reino Unido y España, se contemplan plazos de tiempo para eliminar los embriones que se tienen congelados. 
a) La hiperestimulación ovárica tiene un rol fundamental en el procedimiento ya que permite obtener varios óvulos en un solo ciclo que son aspirados con una única punción con guía ecográfica. Hoy se considera que la hiperestimulación con gonadotropinas podría tener efectos negativos en la ovogénesis, en la salud del embrión obtenido, en la receptividad endometrial y en los resultados perinatales, menguando de esta manera la tasa de embarazos y la salud de los bebés que llegan a nacer; en la actualidad es necesario tener más conocimientos para poder incrementar la seguridad de la estimulación ovárica y reducir así los posibles efectos sobre el desarrollo e implantación del embrión (cf. Avo Santos et ál 2010).

b) Epigénesis y enfermedades asociadas: desde inicios de esta década varios reportes, confirmados por estudios recientes (cf. Katari 2009; Owen 2009), han sugerido que pueden haber desordenes en el fenómeno epigenético ${ }^{5}$ conocido como imprinting en los niños concebidos por TERA, específicamente los síndromes de BeckwithWiedemann y de Angelman. ${ }^{6}$ La baja ocurrencia de estas patologías y lo variable de los protocolos seguidos en las diferentes clínicas donde se realizan las TERA no permiten tener hoy conclusiones definitivas. Sin embargo, los modelos animales muestran que el

5 Epigénesis implica el control de genes por factores diferentes a una secuencia de DNA de un individuo. Los Cambios epigenéticos pueden "activar» o "desactivar» (o «silenciar») los genes, determinando así cuál proteína se transcribe y cuál no. La metilación del DNA es un modo de «silenciar» genes.

6 El síndrome de Angelman se caracteriza por discapacidades del desarrollo, convulsiones, déficit del habla, y torpeza motora. Ocurre aproximadamente en 1/15-20 mil habitantes y lo causan alteraciones epigenéticas en el cromosoma 15. El síndrome de BeckwithWiedemann se caracteriza por macrosomía al nacer y predisposición a los tumores; su causa son alteraciones epigenéticas en el cromosoma 11. 
procedimiento de las TERA sí pueden alterar el imprinting normal, específicamente la metilación del DNA, que es responsable de establecer los patrones de expresión y, en definitiva, la función de numerosos genes. Otros autores (cf. Grace 2009), han señalado la asociación con otras alteraciones epigenéticas quizá menos conocidas, cuyas consecuencias para la salud que no se manifiestan hasta la edad adulta, según la evidencia acumulada a partir de estudios con animales; y postulan que este - y no tanto los cambios tempranos luego del nacimiento- sería el verdadero legado de las TERA en el desarrollo del individuo humano, lo que describen como «una bomba de tiempo aún activa». Últimamente un estudio ha encontrado un riesgo incrementado de retinoblastoma en niños concebidos por FIV en los países bajos, patología que también estaría asociada a alteraciones en la epigénesis (Marees 2009). Son necesarios estudios prospectivos para valorar mejor la alteración de la epigénesis por los procedimientos llevados a cabo en la reproducción asistida.

c) Número de embriones transferidos y embarazos múltiples: una de las causas del bajo rendimiento de las TERA es el fracaso de la buena implantación del embrión transferido en el endometrio materno; lo cierto es que a pesar de todos los avances en las investigaciones, aún se desconoce mucho de los aspectos del proceso de implantación y su natural regulación. A pesar de que los técnicos de la reproducción asistida han establecido criterios de selección para quedarse con los embriones «más aptos» y eliminar al resto, no es posible predecir con certeza cuál y cuántos de los embriones trasplantados llegarán a anidar en el endometrio uterino. De allí que sea necesario transferir 
dos o más embriones en el tracto genital femenino para incrementar las posibilidades de éxito.

En EEUU donde rutinariamente se trasfieren 2 ó más embriones, en el año 2003 el 35\% de los nacimientos vivos alcanzados mediante TERA fueron de embarazos múltiples con dos o más bebés (cf. Centers for Disease Control and Prevention 2007); mientras que la incidencia es de menos del 2\% cuando la concepción es natural (cf. ESHRE Capri Workshop Group 2000). En Europa en promedio se trasfieren menos embriones que en EEUU, sin embargo la incidencia de embarazos múltiples alcanzan el 25,5\% (cf. Andersen 2005).

Es sabido que los embarazos múltiples se asocian con riesgos importantes y resultados adversos para la salud de la madre y la vida y la salud de los fetos. Para estos últimos — si alguno no muere a causa de un aborto - existe un riesgo importante de bajo peso al nacer, parto pre-término, mortalidad perinatal y discapacidad entre los bebés que sobreviven (cf. Vayena 2002). Algunos han propuesto que los esfuerzos de los investigadores de TERA deben orientarse a lograr el nacimiento de un único bebé (Vayena 2002; ESHRE Capri Workshop Group 2002). La estrategia más efectiva para reducir los nacimientos múltiples es transferir un único embrión, pero ello es minoritariamente aceptado entre los que se dedican a la reproducción asistida, y de hecho es poco llevado a la práctica, dada la pobre posibilidad de que así se logre el nacimiento de un bebé vivo (cf. Schiave 2006). Por eso, sigue siendo práctica corriente en la actualidad la transferencia de 3 ó más embriones; y la alternativa que se ofrece, largamente con más frecuencia, a la mujer que tiene un embarazo múltiple de alto orden es la «reducción de embarazo multifetal» $\mathrm{o}$ «reducción embrionaria». 
d) El «fenómeno del embrión desaparecido»: alude al hecho no infrecuente en gestaciones naturales que comienzan con dos o más bebés, pero que terminan con un número menor de nacidos vivos por «desaparición» de uno o más embriones; dichos embriones literalmente desaparecen, siendo su restos supuestamente absorbidos por los tejidos de la madre o de los embriones que le sobreviven. El hecho ha sido descrito, pero se desconocen las causas por las que ocurre y sobre todo cuál es el impacto real de esto sobre el embrión que sobrevive. Por ejemplo, una de las hipótesis planteadas para el caso de mellizos, es que el «fenómeno del embrión desaparecido» sería la causa de la parálisis cerebral espástica en el bebé que sobrevive. El incremento de las TeRA ha llamado la atención sobre el «fenómeno del embrión desaparecido», ya que teniendo una mayor incidencia de embarazos con 2 ó más bebés, constituyen el escenario para que la «desaparición» de un embrión se dé con frecuencia, ya sea por imperfecciones de la misma técnica, ya sea por la llama "reducción embrionaria» a manos del operador. Así, se ha encontrado, por ejemplo, que es más probable que los bebés nacidos por FIV sean de bajo peso si en el embarazo hubo «embriones desaparecidos»; o que el tiempo de gestación es inversamente proporcional al número de sacos gestacionales que hubo al inicio del embarazo. Una investigación ha encontrado indicios de un riesgo incrementado de parálisis cerebral entre niños generados mediante FIv/ICsi (cf. Hvidtjørn 2005), nacidos de embarazos en los que el número de embriones transferidos fue mayor que el número de niños que finalmente nacieron, concluyendo los autores que la asociación entre la «desaparición» del embrión y la incidencia de 
parálisis cerebral en FIV requiere ser investigado más ampliamente y con mejores estudios.

e) La eficacia de la técnica: según los últimos reportes, las tasas de éxito para las TERA se han incrementado a nivel mundial, pero en pequeño porcentaje. Para EEUU, en las estadísticas del año 2009 (cf. Centers for Disease Control and Prevention 2011), solo el $30 \%$ de los ciclos iniciados - es decir, las mujeres que iniciaron un procedimiento de TERA- culminaron en un niño nacido vivo. Este el porcentaje de éxito que las personas están más interesadas en saber porque representa la posibilidad de tener uno o más niños nacidos vivos recurriendo a TERA. De las mujeres de las que se lograron obtener óvulos y consecuentemente embriones in vitro, aproximadamente el 34\% logró el ansiado bebé en brazos; del total de embriones transferidos el $55 \%$ se perdió sin poder implantarse y lograr el embarazo; y solo poco más de la tercera parte $(37 \%)$ llegaron a nacer vivos. Estos porcentajes se hacen menores con el aumento de edad de la mujer, porque se ha demostrado que la FIV puede remontar la infertilidad en mujeres jóvenes, pero no revierte la declinación de la fertilidad femenina ligada a la edad, que tiene como principal punto de corte los 35 años de vida. Estas cifras no han variado sustancialmente respecto a reportes anteriores. Tasas similares a las de EEUU se encuentran en los países europeos (Andersen 2005). Para hacer más clara la idea de lo experimental del proceso, jamás sería aceptado un tratamiento médico —entiéndase: una medicina - para ser usada en humanos con un porcentaje tan bajo de eficacia. En otras palabras, sigue siendo una realidad que la mayoría de mujeres que inicia un ciclo se retira sin el ansiado hijo; 
y en el camino, entre selección embrionaria, reducción embrionaria (o reducción fetal de embarazo múltiple) y aquellos embriones que no llegan a implantarse, y los que una vez implantados no logran completar su desarrollo y llegar al parto, las pérdidas de embriones y fetos es abrumadoramente alta. Las muertes ocurren no solo en las primeras semanas o en el laboratorio, sino cuando - por la morfología externa del ser en desarrollo - no queda duda de que nos encontramos ante un individuo de la especie humana, ante un niño en espera de nacer.

Lo revisado en este primer paso nos permite concluir que las TERA, y particularmente la FIV, tienen una tasa de éxito muy baja, con varios elementos aún no conocidos científicamente, que requieren mayor investigación, y que por lo mismo escapan al control técnico durante el procedimiento; y que deja abiertas muchas incógnitas acerca de los efectos sobre los niños que finalmente lograrán nacer. Estamos pues, ante un procedimiento que en sentido estricto es un experimento.

\section{VALORES EN JUEGO Y LICITUD ÉTICA}

El problema expuesto en el punto anterior implica una reflexión ética. Esta nos permitirá entrever cuáles son los valores puestos en juego por las TERA, en particular desde la perspectiva de los niños. Dicha reflexión será, además, revisada a través de la perspectiva y los valores concernientes.

\subsection{UN ASUNTO ANTROPOLÓGICO}

Una primera idea que se ha de señalar es que en la raíz de aquellas situaciones problema que constituyen atentados a la dignidad y a la vida de seres 
humanos, y que entran en el campo de estudio de la bioética, encontramos que la respuesta a la pregunta «qquién soy?» o «¿quién es el hombre?», o está ausente porque el hombre no se la ha planteado, o está oscurecida o equivocada en su respuesta. Es que la «ética de la vida» es en realidad un asunto antropológico; y la pregunta antropológica tiene connotaciones sociales evidentes, porque la pregunta «¿quién soy?» es análoga a la pregunta "¿quién es este ante quién estoy?» (cf. Benedicto XVI 2009); es decir, el descubrimiento de mis semejantes está en el fundamento de mis decisiones éticas respecto a la vida. Entonces, para hacer el análisis correcto y encontrar respuestas sobre lo que es lícito o no hacer desde el punto de vista ético, es necesario basarnos en una concepción del hombre que se ajuste a lo que él es real y objetivamente y que contribuya a valorarlo. Ella no puede ser sino una concepción integral del ser humano, que lo entienda como lo que es, un todo cuerpo-mente-espíritu, integrado como unidad y abierto a la trascendencia, que no se queda en lo inmanente, que no solo es materia biológica, sino que posee además una mente y un espíritu. Y entendido así, el ser humano deberá ser puesto al centro de la valoración ética de las TERA y de las otras realidades que son materia de estudio de la bioética, como el valor primordial que ha de ser respetado en su vida y dignidad. Este planteamiento garantizará soluciones a los dilemas que sean respetuosos de la vida y dignidad de todos y cada uno de los seres humanos.

\subsection{LOS VALORES EN JUEGO}

Sobre esta premisa antropológica, ¿cuáles son los valores en juego que se distinguen de los datos biomédicos en relación a las TerA? Desde esta interrogante mencionaremos los siguientes aspectos: 
a) El modo como el ser humano viene a la existencia: los niños que nacen mediante este procedimiento vienen fabricados como objetos o productos de mercado. Hemos recalcado que tras todo problema que amenaza la vida existe un problema antropológico no resuelto, una falla en el modo como se conceptúa al ser humano. El ser humano es un fin en sí mismo y no puede ser medio para otro fin. A él solo le corresponde ser querido en sí mismo y por sí mismo.

Al traer a aquellos seres humanos a la existencia del modo como se hace en un procedimiento de reproducción técnicamente asistida se atenta contra su dignidad inherente, porque se les produce y se les trata como objetos. Además, se atenta contra su dignidad porque se les priva del modo de venir a la vida que les es propio, el que les corresponde por ser quienes son; nos referimos al único lugar digno para la procreación humana: el acto de amor conyugal, sin intervención de extraños.

Lo que debería ser "procreación» de un ser humano se convierte por estas técnicas en «reproducción», con una evidente impronta comercial: producir seres humanos según criterios de mercado y - podemos agregar- con un indesligable interés lucrativo.

El rasgo mercantil de las TeRA — donde el hijo es el producto a comercializar - salta a la vista al observar los pasos del procedimiento, ordenado como un proceso de producción donde hay materias primas, controles de calidad, tasa de pérdidas, tasas de rendimiento, etc., orientadas todas a la producción de un bien de consumo que se oferta según la demanda, y por el cual se paga un precio de mercado. También se evidencia cuando se observa que, si bien se dice que 
surgieron como una compasionada ayuda a la pareja de cónyuges estéril, hoy se ofrecen — también por «compasión»— a un mercado bastante más amplio y diversificado de interesados en «tener un hijo», y que pueden "pagarlo», como son hombres y mujeres, solteros por opción o en parejas, heterosexuales $\mathrm{u}$ homosexuales.

Debemos preguntarnos jel deseo de tener un hijo y tener la capacidad económica para intentarlo recurriendo a las TERA me da derecho a atentar de esa manera contra la dignidad del ser humano? Podemos recordar aquí el caso peruano de la niña Marianita que al ser considerada por su padre como «un producto fallado» por presentar síndrome de Down, fue motivo de un reclamo a la clínica Concebir. ${ }^{7}$ ¿Debe permitirse el atropello de la dignidad de un ser humano débil porque otros se creen con derecho a tener un hijo?, ¿existe el derecho al hijo?, ¿es que acaso un ser humano puede tener derecho de «tener» un ser humano?, ¿no es ese más bien el trato que se le da a una cosa?

Asimismo, preguntémonos ¡existe el derecho a comercializar tejidos humanos, como son los gametos?; o más aún, ¿existe el derecho a comercializar seres humanos sacando ventaja del hecho de encontrarse en la etapa embrionaria de su vida?, ¿puedo «donar» un ser humano sobrante de una fertilización in vitro? ¿Es que se trata solo de regularlo mediante leyes civiles, para que el proceso tenga orden, para que no se llegue a demasiados excesos?, ¡es que no es un exceso el hecho mismo de comercializar con un ser humano? No existe

El año 2010, una pareja de esposos presentó una demanda contra una clínica de fertilidad en la ciudad de Lima porque una de las dos hijas nacidas recurriendo a las Tera, llamada Mariana, presentaba Síndrome de Down. Aducían sentirse estafados por haber recibido «un producto fallado» (cf. Meier 2010, Paccini 2010). 
diferencia sustancial en el ser humano según el estadío de desarrollo que se encuentre: vale tanto si ya es adulto, como si es niño, nacido o por nacer. Hoy parece que la compasión por los adultos que quieren tener hijos — lo que algunos llaman «razones humanitarias»— prima más que los intereses de los niños por nacer.

b) Filiación e identidad: las TERA presentan, entre sus diferentes escenarios, al médico y biólogo como participantes de la paternidad, al donante (o donantes) de gametos como reales padre y madre genéticos, y a la portadora del embarazo como «madre» biológica, que no necesariamente coincide con aquella que aporta el gameto. La intervención de otras personas extrañas a los padres en la concepción del hijo, la no coincidencia entre los padres genéticos, los biológicos y los sociales que se da en las TERA es una disrupción que atenta contra la dignidad del niño que nacerá, al atentar contra su filiación —es decir, el derecho que tiene a ser hijo de un único padre y una única madre reconocidos - y en última instancia contra su identidad.

Ya hemos mencionado que las Tera han abierto las puertas a las formas de filiación más bizarras que hoy son realidad, por mencionar solo algunas: madres de más de 65 años; mujer madre y a la vez tía o abuela de su hijo; dos padres sociales que pueden ser del mismo sexo, una madre biológica y otros dos genéticos; tres madres, una genética, otra biológica y la social (quien encargó el procedimiento); o tener decenas o cientos de hermanos de padre, o de madre, sin conocerlos.

Aún no se han valorado suficientemente el impacto de estos entuertos en la psicología del hijo, del padre y de la madre, y en las 
relaciones padre-hijo o madre-hijo, que también sufre alteraciones. Sin embargo, las TERA siguen en marcha.

El asunto de la filiación y consecuentemente la identidad atropelladas, aunque atañe a todas las TERA se ve más claramente en el caso de la concepción con donación de gametos. Un reciente estudio titulado «Mi papá se llama donante» (cf. Marquardt 2010, la traducción del título es mía), encuentra que los individuos concebidos con semen donado están más heridos, están más confundidos, y se sienten más aislado de sus familias, comparados con sus pares criados por padres biológicos; les va peor en rubros como depresión, delincuencia y abuso de sustancias; sienten que el donante es «la mitad» de lo que ellos son, y se sienten afectados por el hecho de que en su concepción haya habido dinero de por medio. $\mathrm{Y}$ en su gran mayoría les preocupa o tienen serias objeciones a la práctica de concebir con gameto donado (es decir, el modo como ellos fueron concebidos), aunque se aduzca como atenuante que los padres pretendan decirle la verdad al niño cuando nazca.

El título del estudio fue tomado de unas camisetas que se venden a los padres de niños que fueron concebidos con gameto donado, diseñado con la intención de ser gracioso. Los autores comentan: «nos preguntamos si les parecerá gracioso a esos niños cuando crezcan» (Marquardt 2010: 6). ¿No sería bueno que escuchemos el reclamo de esos niños a tener un padre y de una madre, a no proceder de fecundaciones o gestaciones aberrantes?, ¿por qué no inclinar la balanza a favor de los intereses del niño en vez de inclinarla a favor de los intereses de los adultos y lo que quieren hacer? 
c) La vida de los hijos generados en el procedimiento: es evidente que las TERA atentan contra el principio bioético fundamental de promoción y defensa de la vida física (cf. Sgreccia 2009: 218). La baja tasa de eficacia de las TERA hacen de ellas un atentado flagrante contra la vida de los seres humanos reproducidos en el procedimiento; una moneda en el aire le daría más probabilidades de vida a un ser humano que las que tiene en un laboratorio de TERA.

¿Por qué siendo este un punto tan claro y evidente desde el punto de vista científico no es respetado? Las explicaciones son complejas y escapan a lo estrictamente científico e incluso al plano únicamente racional. Sin embargo, vale la pena mencionar las falacias con las que se busca confundir la razón y así justificar éticamente esta grave ilicitud:

- Principalmente, la compasión por la mujer o la pareja de cónyuges que sufre por no tener un hijo;

- además, el lenguaje confuso usado para ocultar lo que en realidad son actos con los que se elimina embriones, como «selección embrionaria» o «reducción fetal de gestación múltiple»;

- por otro lado, la poca honestidad científica, con la que pretenden poner en duda o relativizar el momento del inicio de la existencia de un ser humano, ignorando por completo que la embriología demuestra que la fecundación o concepción es el «tiempo cero» de la existencia de todo ser humano; 
- a su vez otros planteamientos, con más argucia, pretenden equiparar las pérdidas espontáneas de embriones que ocurren naturalmente a las pérdidas que tienen como causa primera a las TERA; cuando la premisa es dirimente desde el punto de vista ético: no es lo mismo que un daño ocurra espontáneamente a que este ocurra como consecuencia de una acción libre y responsable hecha por una persona.

La vida humana, como se aprecia en todo ser humano vivo, es ante todo un valor natural, racionalmente reconocido por quienes hacen uso de la razón. Estamos ante un valor intangible: es un valor primario y absoluto, y no relativo. Nada puede subordinarla, en cuanto que la vida física es el primer valor que hemos de proteger en todos y cada uno de los individuos pertenecientes a la familia humana, en quienes además la reflexión metafísica que es insoslayable y que no puede ser marginada por la bioética en cada uno de los problemas críticos que trata, descubre el valor de persona. ${ }^{8}$

d) La salud: además de la vida, como hemos visto, se atenta también contra la salud de los seres humanos concebidos por FrV. El Principio de responsabilidad categorizado por el pensador alemán Hans Jonas (Jonas 1995), es considerado una de las más grandes contribuciones para la bioética ya en sus orígenes. Jonas, observaba hace más de treinta años, coincidiendo con los primeros nacimientos de «bebés probeta», que cada vez era más posible que la técnica constituya una amenaza para la supervivencia de la humanidad, llamada justamente

$8 \mathrm{Al}$ respecto un referente de esta escuela bioética que pone como medida de la valoración de los dilemas éticos al ser humano en cuanto persona integrada en su cuerpo, mente y espíritu, con apertura a la trascendencia (cf. Sgreccia 2009). 
a sobrevivir. Por ello propuso una ética fundada sobre el examen de las consecuencias de las intervenciones del ser humano en la biosfera, teniendo como criterio guía la exclusión de la catástrofe. En otras palabras, ningún ser humano tiene derecho a arriesgar la vida o la salud de nadie a causa de los efectos a largo plazo de sus acciones hoy. Un ejemplo de la vigencia rectora de este principio de la bioética lo constituye la moratoria internacional respecto a la clonación reproductiva, que la UNESCO ha liderado sin encontrar resistencias en los estados del globo, dado que es un procedimiento que encierra muchos riesgos desconocidos para la humanidad, no solo en los aspectos biológicos sino también en los éticos y sociales. Aquí frente a las TERA no solo nos encontramos en una situación análoga en cuanto a desconocimiento y poca valoración ética de las consecuencias de salud, sociales y culturales que recaerán sobre los seres humanos directamente vulnerados por ellas, como son los niños que finalmente llegarán a nacer.

Si el cuidado por las generaciones futuras que nos señala el principio de responsabilidad se nos presenta sensato y de necesaria aplicación cuando se trata de proteger el medio ambiente, las diferentes especies vivas que constituyen la biodiversidad y el equilibrio ecológico, ¿no debería ser aplicado a una realidad como las TERA donde los que están en riesgo son los niños que nacerán y sobre todo los que no nacerán? ¿Por qué las TERA siguen su curso como si fuera lícito exponer la vida y poner en riesgo la salud de todos los seres humanos que mueren o pueden salir afectados en el proceso en el futuro? ¿En qué se sustenta su derecho de disponer y exponer la vida y la salud de esos seres humanos?, ¡en que la ciencia está 
en la capacidad de hacerlo y nadie puede detenerla?, `en que un interesado paga para que se proceda a la TERA?

e) Consentimiento informado: pareciera que hablar de consentimiento informado se refiere solo a los adultos. Ciertamente en el contexto de las Tera es de capital importancia que los adultos sean adecuadamente informados sobre lo que ocurre en un procedimiento así. En torno a las TERA existe una generalizada falta de transparencia y claridad en la información dada a los solicitantes. Gran parte de quienes se acercan a indagar sobre las TERA están desinformados o ignoran la realidad encubierta tras el manto rosa de una tierna fotografía que hace propaganda a una clínica que ofrece el procedimiento. Informar que «nadie sabe en qué momento comienza a existir un ser humano», o que "antes de la implantación en la cavidad uterina no es un ser humano»; encubrir con un lenguaje engañador («selección embrionaria», «reducción embrionaria») aquellos pasos del procedimiento técnico que consiste en quitar la vida a seres humanos de pocos días de existencia, y que son también hijos de la pareja solicitante, es atentar contra la libertad o autonomía de la persona para elegir libre y responsablemente, y de modo correctamente informado. Pero las técnicas reproductivas in vitro manipulan a seres humanos en estadío embrionario y fetal en procedimientos que son experimentales y que los expone a los riesgos ya citados. ¿Aquellos seres humanos no deberían tener derecho a objetar o no debería alguien objetar por ellos? La experimentación no terapéutica — como es el caso de las

9 Es muy sugerente la reflexión de Benedicto XVI sobre el «rostro ambiguo» que presenta la técnica, al ser una expresión del espíritu del hombre, y por ello ligada a su autonomía y libertad. (cf. Benedicto XVI 2009: 109-112). 
TERA - en sujetos incapaces de dar su consentimiento — como es el caso de los embriones- no es éticamente lícita.

\section{COMENTARIOS FINALES A MODO DE CONCLUSIÓN}

El ejercicio bioético de aproximarse a las Técnicas de Reproducción Asistida desde la perspectiva del niño, permite descubrir elementos objetivos que desde la perspectiva de los adultos y sus intereses - usualmente envuelta en sentimientos de compasión - no son tomados en cuenta en la reflexión ética sobre las TERA, y las consecuencias que de esta reflexión se han de derivar, como son las que se refieren al Derecho y las leyes.

Por sus elementos técnicos y biológicos aún ignorados en gran parte, por los aspectos de los procedimientos técnicos aún no validados científicamente, y por su tan baja eficacia para lograr el ansiado bebé en brazos, las TERA constituyen un procedimiento experimental con graves repercusiones sobre los infantes. Estos se ven afectados en la dignidad de su procreación, en sus relaciones de filiación; en su autonomía, al ser usados como sujetos de experimentación sin ser capaces de dar su consentimiento para ello, lo cual dará como inevitable resultado la pérdida de sus vidas o el daño a su salud.

Por lo tanto, podemos afirmar que las TERA, así como las conocemos hoy, por las repercusiones negativas insalvables que tiene sobre los niños que nacerán y que no nacerán a causa de ellas, no pueden ser consideradas éticamente lícitas desde ningún punto de vista.

Es necesario atreverse a ver las TERA desde la perspectiva de los niños y ponerse del lado de ellos. Las disyuntivas que enfrentamos no admiten términos medios: o se favorece el desarrollo de la ciencia y de la técnica, o se 
está de la parte de los niños; o se favorece el interés de los adultos, o se está de parte de los niños. ¿A quién se debe proteger?, ¿a favor de quien se debe inclinar la balanza? Para llegar a la respuesta justa no se puede prescindir de la verdad de los hechos científicos documentados sobre las TERA, ni de las realidades socioculturales que observamos como consecuencia de su aplicación, de las que los niños son las primeras víctimas y de la misma forma todos nosotros. En consecuencia, le tocará al Derecho garantizar la protección de los más débiles e indefensos de la familia humana, en beneficio de toda la sociedad. 


\section{BIBLIOGRAFÍA}

Andersen, Nyboe; L. Gianaroli; R. Felberbaum; J. de Mouzon y K.G. Nygren

2005

"Assisted reproductive technology in Europe, 2001: results generated from European registers by ESHRE». Human Reproduction, Vol. 20, N. 5 , pp. $1158-1176$.

Avo Santos, Margarida; Ewart W. Kuijk y Nick S. Macklon 2010 "The impact of ovarian stimulation for IVF on the developing embryo». Reproduction, Vol. 139, N. 1, pp. 23-34.

Batcheller, April; Eden Cardozo; Marcy Maguire; Alan H. DeCherney y James H. SEgars

2011

"Are there subtle genome-wide epigenetic alterations in normal offspring conceived by assisted reproductive technologies?». Fertility and Sterility, Vol. 96, N. 6, pp. 1306-1311.

Benedicto XVI

2009

Caritas in veritate. Lima: Paulinas. 
Centers for Disease Control and Prevention; American Society for Reproductive Medicine; Society for Assisted Reproductive Technology 2007 2005 Assisted Reproductive Technology Success Rates: National Summary and Fertility Clinic Reports». En Centers for Disease Control and Prevention. <http://www.cdc.gov/art/ ART2005/508PDF/2005ART508.pdfs. Consulta hecha en $31 / 11 / 2012$.

Centers for Disease Control and Prevention; American Society for Reproductive Medicine; Society for Assisted Reproductive Technology 2011 «2009 Assisted Reproductive Technology Success Rates: National Summary and Fertility Clinic Reports». En Centers for Disease Control and Prevention. <http://www.cdc.gov/art/ART2009/ PDF/ART_2009_Full.pdf>. Consulta hecha en $31 / 11 / 2012$.

Davies, Michael J.; Vivienne M. Moore; Kristyn J. Willson; Phillipa Van Essen; Kevin Priest; Heather Scott; Eric A. HaAn y Annabelle Chan 2012 «Reproductive Technologies and the Risk of Birth Defects", New England Journal of Medicine, Vol. 366, N.19, pp. 1803-1813.

ESHRE CAPRI WORKSHOP GROUP 2000 «Multiple gestation pregnancy». Human Reproduction, Vol. 15, N. 7, pp. 1856-1864. 
Grace, Kristen S. y Kevin D. Sinclair 2009

"Assisted reproductive technology, epigenetics, and long-term health: a developmental time bomb still ticking». Seminars in Reproductive Medicine, Vol. 27, N. 5, pp. 409-416.

GugucheVA, Magdalina 2010

«Surrogacy in America», En Council for Responsible Genetics. <http://www. councilforresponsiblegenetics.org/ pageDocuments/KAEVEJ0A1M.pdf>. Consulta hecha en 30/11/2013.

Hvidtjørn, Dorte; Jakob Grove; Diana Schendel; Michael Væth; Erik ERnst; Lene Nielsen y Poul Thorsen 2005

"Short Communication: "Vanishing embryo syndrome" in IVF/ICSI». Human Reproduction, Vol. 20, N. 9, pp. 2550-2551.

JonAs, Hans

1995

El Principio de Responsabilidad: ensayo de una ética para la civilización tecnológica. Barcelona: Herder.

Katari, Sunita; Nahid Turan; Marina Bibikova; Oluwatoyin Erinle; Raffi Chalian; Michael Foster; John P. Gaughan; Christos Coutifaris y Carmen SAPIENZA

2009

«DNA methylation and gene expression differences in children conceived in vitro or in 
vivo». Human Molecular Genetics, Vol. 18, N. 20, pp. 3769-3778.

Marees, T.; C.J. Dommering; S.M. Imhof; W.A. Kors; P.J. Ringens; F.E. VAN LeEuWen y C. Moll 2009

"Incidence of retinoblastoma in Dutch children conceived by IVF: an expanded study». Human Reproduction, Vol. 24, N. 12, pp. 3220-3224.

Marquardt, Elizabeth; Norval D. Glenn y Karen Clark 2010 My Daddy's Name is Donnor. A New Study of Young Adults Conceived Through Sperm Donation. En Family Scholars. <http://www.familyscholars.org/ assets/Donor_FINAL.pdf>. Consulta hecha en $31 / 11 / 2012$.

MeIer, Martha 2010

«La tragedia de Mariana de los Ángeles». El Comercio, Lima, 13 de noviembre 2010, Actualidad, Opinión, p. 45.

Moore, Keith L.; T. V. N. Persaud; Mark G. Torchia 1998

The Developing Human: Clinically oriented embryology. 6. ${ }^{\text {a }}$ ed. Philadelphia: W.B. Saunders Company 
Mouzon, Jacques de; Paul Lancaster; Karl Gosta Nygren; Elisabeth Sullivan; Fernando Zegers-Hochschild; Ragaa Mansour; Osamu IsHIHARA y David ADAMSON 2009

«World Collaborative Report on Assisted Reproductive Technology, 2002» Human Reproduction, Vol. 24, N. 9, pp. 2310-2320.

O’Rahilly, Ronan y Fabiola Muller 2001 Human Embryology \& Teratology. 3. a ed. New York: Wiley-Liss.

Owen, Carter M. y James H. Segars 2009

«Imprinting Disorders and Assisted Reproductive Technology». Seminars in Reproductive Medicine, Vol. 27, N. 5, pp. 417-428.

Paccini, Renzo

2010

«Un lobo con piel de cordero». El Comercio, Lima, 14 de noviembre 2010, Actualidad, Opinión, pp. 44.

Pearson, Helen

2002

«Developmental Biology: Your destiny from day one». Nature, Vol. 418, N. 6893, pp. 14-15.

Schieve, Laura A.

2006

"The promise of single embryo». New England Journal of Medicine, Vol. 354, N. 11, pp. 11901193. 
SERra, Angelo

2003

L'uomo-embrione. Il grande misconosciuto. 1. ${ }^{\mathrm{a}} \mathrm{ed}$. Siena: Cantagalli.

SGreCCIA, Elio

2009

Manual de Bioética. 1. ${ }^{\mathrm{a}}$ ed. Tomo I: Fundamentos y ética médica. Madrid: Biblioteca de Autores Cristianos.

SGReCCIA, Elio y Jean LAfFitte (comp.) 2008

El embrión humano en la fase de pre-implantación. Aspectos científicos y consideraciones bioéticas. Madrid: Biblioteca de Autores Cristianos.

UNIVERSIDAD DE STANFORD 2008 "Introduction: The Growth of Commercial Surrogacy in India». En Surrogate Motherhood in India. Understanding and Evaluating the Effects of Gestational Surrogacy on Women's Health and Rights. <http://www.stanford.edu/ group/womenscourage/Surrogacy/index.html>. Consulta hecha en 31/11/2012.

Vayena, Effy; Patrick J. Rowe y P. David Griffin 2002 «Current Practices and Controversies in Assisted Reproduction. Report of a meeting on "Medical, Ethical and Social Aspects of Assisted Reproduction" held at WHO Headquarters in Geneva, Switzerland, 17-21 September 2001». En 
World Health Organization. <http://whqlibdoc. who.int/hq/2002/9241590300.pdf>. Consulta hecha en 30/11/2013.

Zegers-Hochschild, Fernando; David Adamson; Jacques de Mouzon; Osamu Ishihara; Ragaa Mansour; Karl G. Nygren; Elisabeth Sullivan y S. VAN Der Poel 2009

«The International Committee for Monitoring Assisted Reproductive Technology (ICMART) and the World Health Organization (WHO) Revised Glossary on ART Terminology, 2009». Human Reproduction, Vol. 24, N. 11, pp. 26832687. 